\title{
Chemoradiotherapy in Cancer Treatment: Rationale and Clinical Applications
}

\author{
KATHRINE S. RALLIS ${ }^{1,2}$, THOMAS HO LAI YAU ${ }^{2}$ and MICHAIL SIDERIS ${ }^{3}$ \\ ${ }^{1}$ Barts Cancer Institute, Queen Mary University of London, London, U.K.; \\ ${ }^{2}$ Barts and The London School of Medicine and Dentistry, Queen Mary University of London, London, U.K.; \\ ${ }^{3}$ Women's Health Research Unit, Queen Mary University of London, London, U.K.
}

\begin{abstract}
Chemoradiotherapy (CRT) refers to the combined administration of both chemotherapy and radiotherapy as an anticancer treatment. Over the years, CRT has become an established treatment for a diverse range of locally advanced solid tumours. The rationale for CRT is based on the two concepts of spatial cooperation and in-field cooperation, whereby the end goal is to achieve synergistic antitumour effects from the combination of both treatment modalities. CRT offers notable patient survival benefits and local disease control without significant long-term toxicities. Although the enhancement of cytotoxic effects inevitably increases damage to normal tissues as well as tumour cells, if the damage to normal tissue is lesser than that to tumour cells, CRT is still deemed beneficial. Thus, the search to optimise dose, timings and fractionation of CRT is of particular interest. Considering the recent success achieved with anticancer immunotherapies including immune checkpoint inhibitors, the combination of CRT and immunotherapy has emerged as an exciting field of research with the potential for significant clinical benefit. This report outlines the rationale underlying CRT and discusses its advantages through clinical examples focusing on anal, cervical, non-small-cell lung cancer and bladder cancer.
\end{abstract}

Chemoradiotherapy (CRT), the concurrent administration of cytotoxic chemotherapy and radiotherapy, has been

This article is freely accessible online.

Correspondence to: Kathrine S. Rallis, MSc, Barts and The London School of Medicine and Dentistry, Turner Street, Whitechapel, London E1 2AD, U.K. Tel: +44 2078822239, Mobile: +44 7526272233, e-mail: k.s.rallis@smd16.qmul.ac.uk

Key Words: Chemoradiotherapy, chemotherapy, radiotherapy, cancer treatment, anal cancer, cervical cancer, non-small cell lung cancer, bladder cancer, immunotherapy, combination treatment, review. established as standard treatment for many locally advanced solid tumours including gastrointestinal malignancies, head and neck cancers, gynaecological cancers, lung cancers, genitourinary cancers as well as glioblastoma and sarcoma. CRT may improve local tumour control and patient survival, while rendering unnecessary the need for surgical organ resection (1-3). Alternatively, CRT may shrink tumours substantially when given neoadjuvantly, thus allowing for curative surgical interventions in patients with tumours initially deemed unresectable (1). The combination of CRT with novel immunotherapies including immune checkpoint inhibitors has emerged as an exciting area of research with many important questions remaining unanswered. Yet the advent of CRT is not recent nor are the theoretical principles underlying its use. This report outlines the rationale underlying CRT and discusses its advantages through clinical examples focusing on anal, cervical, non-small-cell lung cancer (NSCLC), and bladder cancer.

\section{Rationale for the Use of CRT - The "Steel Paradigm"}

CRT is based on the principles of spatial cooperation and radiation 'sensitization' demonstrated in pre-clinical and clinical studies from the 1950s (4-6). Spatial cooperation, a term coined in 1979 by the English scientists, Steel and Peckham, refers to the eradication of subclinical micrometastases by systemic chemotherapy and locoregional irradiation of the primary tumour (5). Interaction between chemotherapy and radiotherapy is not required for spatial cooperation (Figure 1), however, differing toxicities are desired to enable effective dosing of both modalities without dose-limiting toxicities $(2,4)$. Although concurrent dosing of radiotherapy and chemotherapy is often difficult to achieve due to toxicity-driven dose reductions, many studies have successfully demonstrated effective reduction of distant metastases compared to radiotherapy alone. 
Radiation sensitization is the second way in which CRT interacts by a 'supra-additive' or 'additive' effect in 'in-field cooperation' (Figure 1). Supra-additive cytotoxicity suggests a greater effect than using both modalities sequentially, while additive cytotoxicity suggests an effect equal to that in sequential use (Figure 2) (2). Conversely, infra-additive effects refer to radioprotective properties of CRT, whereby cytotoxic damage to tumour and normal tissue is reduced due to interaction of the two therapeutic modalities. Infra-additive effects are typically undesirable when radioprotective effects are observed in tumour cells. However, chemotherapeutic drugs with infra-additive effects can also be chosen to selectively target normal tissue to enhance maximal feasible radiation dose. In theory, radiation sensitization is achieved by five CRT interactions: (i) Direct radiation damage enhancement by drug incorporation into DNA, (ii) cellular repair inhibition, (iii) radiosensitive phase cell accumulation or radioresistant phase cell elimination, (iv) hypoxic cell elimination, and (v) inhibition of accelerated cancer cell repopulation $(2,4)$. Through these mechanisms, chemotherapy sensitizes cancer cells to the effects of ionising radiation, thus increasing tumour-killing effects within the field of radiation (1). Moreover, CRT dose-response curves quantify CRT interaction and although an increase in normal tissue damage is observed, combination therapy is still considered beneficial if a larger increase in cytotoxicity is observed towards the tumour versus normal tissue (Figure 3) (2).

Lastly, in addition to improving the rate of tumour shrinkage and treating micro-metastases, CRT theoretically offers the added benefit of independent toxicity (1). Chemotherapy toxicities do not overlap radiotherapy toxicities, hence sparing additive toxic effects of combination treatment. Moreover, the concomitant use of these treatment modalities confers beneficial responses that can overcome cancer resistance to individual treatments $(1,2)$. Although concurrent CRT inevitably increases acute toxicities by enhancing normal cell damage, late toxicities are not significantly increased. Therefore, CRT offers a therapeutic benefit without significant toxicity risk while improving local disease control and survival. Of note, the temporal distribution of chemotherapy and radiotherapy is important as induction chemotherapy followed by radiotherapy does not always improve local disease control rates (4).

\section{CRT in Anal Cancer}

The first promising results of CRT were observed in the treatment of anal cancer in the 1970s. Three patients treated neoadjuvantly with fluorouracil and mitomycin $\mathrm{C}$ plus radiation achieved complete responses. Histologically confirmed complete response was observed in two patients and the third experienced a progression-free survival of 14 months (7). Results from subsequent clinical trials were equally promising. Today, CRT with 5-fluorouracil plus mitomycin $\mathrm{C}$ is offered as mainstay curative treatment for anal squamous cell carcinomas with the intent of organ preservation after having repeatedly been shown to be a superior treatment in large-scale clinical trials (8-12). Abdominoperineal resection surgery with formation of end colostomy is reserved for salvage or secondary therapy after disease progression following CRT (13). Furthermore, highdose irradiation with brachytherapy in patients with residual disease after CRT achieves higher rates of local disease control, and although this has been criticised for increased risk of adverse events, these remain statistically insignificant (13-15). Finally, intensity-modulated radiation therapy, provides a means of delivering curative radiotherapy in CRT without treatment gaps. Intensity-modulated radiation therapy facilitates dose escalation, reduces dosing to surrounding normal critical structures, and maintains excellent targeted tumour coverage (13, 16-18). Nevertheless, these benefits from intensity-modulated radiation therapy do not necessarily correlate to an improved overall survival (OS) (16).

\section{CRT in Cervical Cancer}

In locally advanced cervical cancer, including stage IB2-IVA disease, CRT remains standard treatment. A large 14-year randomised trial concluded that cisplatin-based CRT offers superior disease-free survival compared to neoadjuvant chemotherapy followed by radical surgery $(76.7 \%$ versus $69.3 \%$ ) (19). Although CRT was found to carry significantly higher risk of rectal, bladder, and vaginal toxicities at 90 days after treatment, these were not significantly different between arms at 24 months for all except vaginal toxicity (19). Furthermore, patients with locally advanced cervical cancer treated with CRT can be stratified into high risk and low risk according to prognostic factors, including lymph node enlargement, tumour diameter, pre-treatment haemoglobin level and clinical stage (20). Novel treatment strategies need to be assessed in high-risk patients to improve outcomes. The most promising novel treatment for high-risk patients has been adjuvant chemotherapy following CRT, while recent studies of metachronous chemotherapy in CRT have yielded promising results in high risk patients who received weekly neoadjuvant carboplatin/paclitaxel chemotherapy followed by radical chemoradiation (21-24).

\section{CRT in NSCLC}

The advantages of chemoradiation are also well established in NSCLC, stage III unresectable non-metastatic disease (25). Lung cancer is the leading cause of cancer-associated death worldwide. NSCLC accounts for $80-85 \%$ of lung cancer cases. The majority of patients with NSCLC are diagnosed with non-resectable disease and $>30 \%$ of cases are 


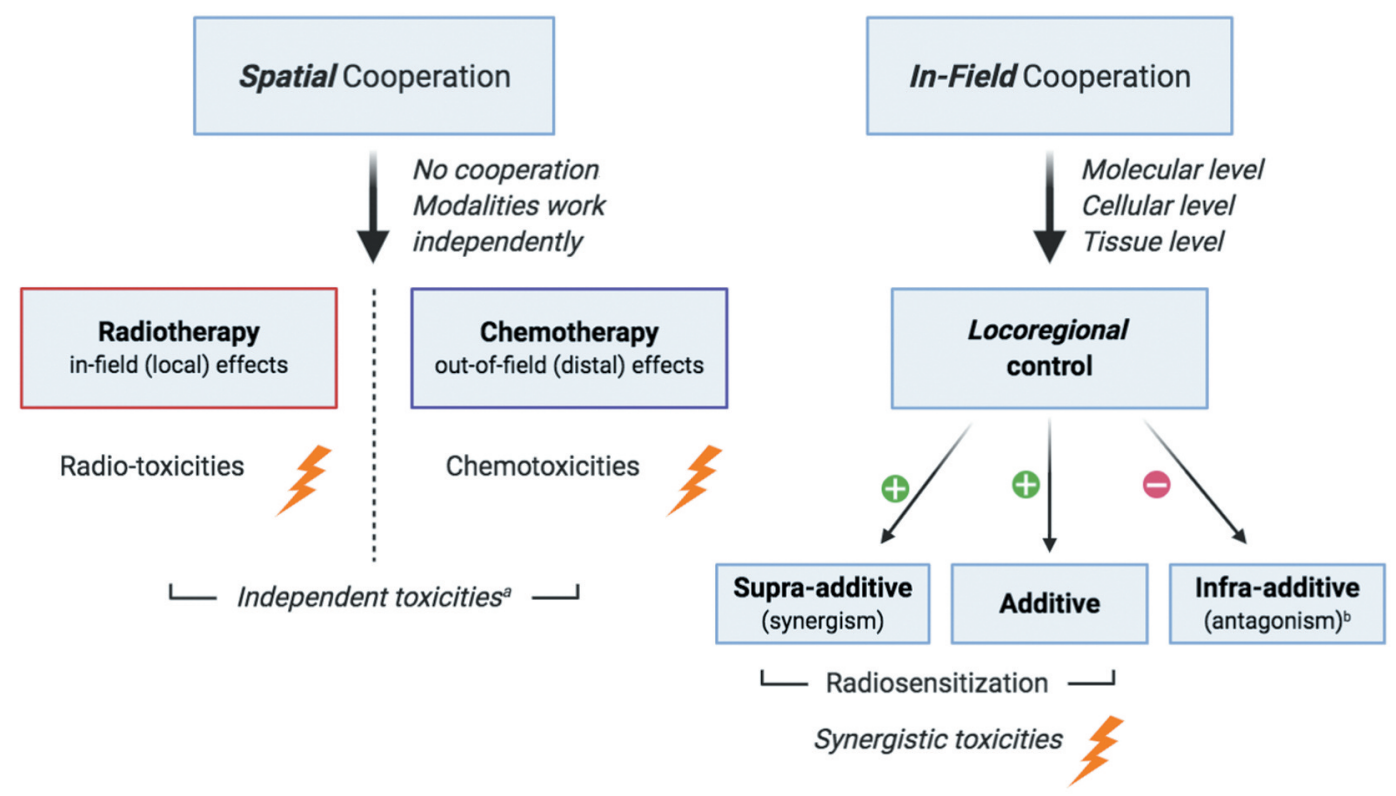

Figure 1. Idealised theoretical framework for concurrent chemoradiotherapy. The two distinct mechanisms describing the interaction of chemotherapy and radiotherapy are spatial and in-field cooperation. ${ }^{a}$ Theoretical advantage of chemoradiotherapy as increased toxicity is often observed in clinical application. ${ }^{b}$ Typically undesirable as it may confer tumour protection. Adapted from (2).

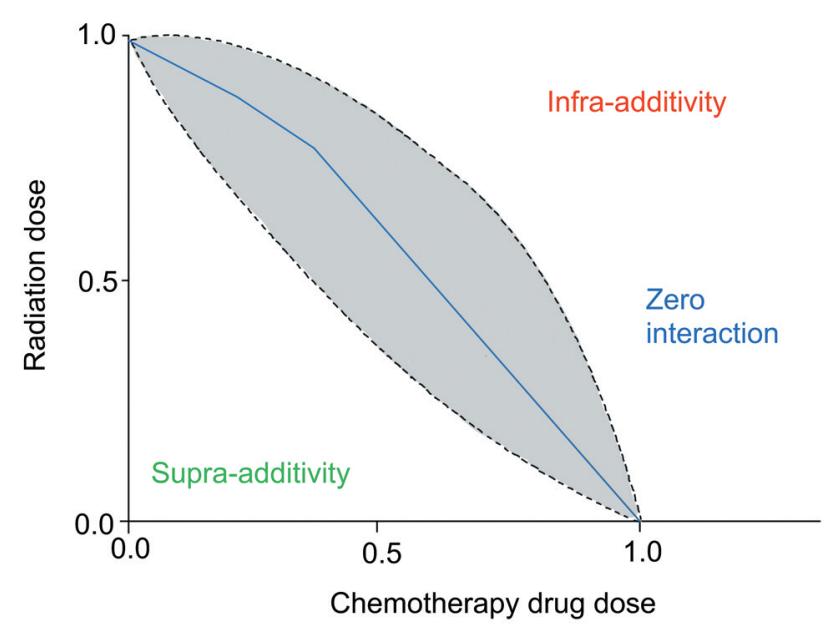

Figure 2. Schematic isobologram demonstrating the possible effects resulting from the combination of radiotherapy and chemotherapy. The $x$ and $y$ axes represent the isoeffective levels for chemotherapy and radiation dose, respectively. The blue line demonstrates additive cytotoxicity whereby the combination of both therapies confers effects equal to sequential use. The additivity envelope, shaded in grey, is based on combined standard errors. Anything above the additivity envelope curve represents an infraadditive antagonistic effect, while anything below the additivity curve represents a supra-additive synergistic effect. Adapted from (2).

locally advanced (26). Radiotherapy alone has been the standard approach for stage IIIA/B NSCLC offering reasonable response rates, however, outcomes with this were poor featuring low survival, poor local disease control, and

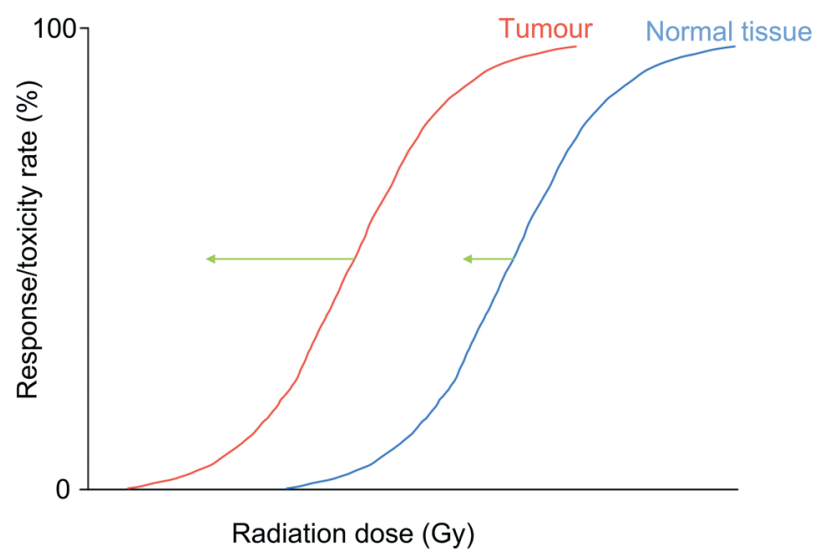

Figure 3. Dose-response curves for tumour cells (in red) and normal tissue (in blue) versus radiation dose. The addition of concurrent chemotherapy increases radiotherapy efficacy as indicated by the green arrows shifting both curves to the left. A stronger shift is desired for the tumour curve, as indicated by the longer arrow, in order for chemoradiotherapy to be deemed beneficial. Adapted from $(2,4)$.

early metastases; with median survival of 9-11 months, 2year survival of $10-20 \%$, and 3-year survival of only $5-10 \%$ $(27,28)$. Furthermore, disease heterogeneity requires a multidisciplinary treatment approach which caused disagreement on the best standard of treatment $(25,29)$.

With sequential CRT, an increase in OS from 5\% to $10 \%$ was noted at 5 years (30-32). This rate was increased to $15 \%$ with concurrent CRT, with a $4.5 \%$ absolute survival benefit 
(33). Although OS improved with concurrent CRT therapy, sequential therapy carries less toxicity risk for oesophagitis and pneumonitis $(34,35)$. Hence, concurrent CRT is preferred for fit patients while sequential therapy is preferred for the elderly or unfit patients $(25,35)$. Currently, the custom treatment for localised inoperable NSCLC is concurrent CRT with a platinum-based doublet and $60 \mathrm{~Gy}$ radiotherapy delivery daily over 6 weeks followed by two cycles of consolidation chemotherapy, particularly for paclitaxel and carboplatin regimens (36). Yet although the current regimen has curative intent, survival rates are low with median survival of 20-28 months and 5-year OS of 15$20 \%$, which has plateaued (37).

Combination of CRT with immunotherapy in NSCLC. With the advent of immunotherapy, and with exceptional results shown thus far in the treatment of advanced NSCLC with programmed cell death protein 1 (PD1) and programmed cell death ligand-1 (PD-L1) immune checkpoint inhibitors, several studies are underway (38-42) to evaluate CRT-immunotherapy combination in the setting of NSCLC (37). Radiotherapy can modulate the immune system and mount an immune response causing immunogenic cell death by enhancing tumour antigen retrieval (43). Additionally, radiotherapy has pro-immunogenic effects on the tumour microenvironment, initiating innate and adaptive immunity $(44,45)$. The abscopal effect, whereby patients exhibit diffuse systemic response to radiotherapy at distant sites after local radiotherapy administration, has generated substantial interest following promising results in metastatic melanoma treated with ipilimumab, an antibodybased cytotoxic T-lymphocyte-associated protein-4 immune checkpoint inhibitor, and response is thought to be driven by T-cells $(43,46)$. A recent phase I trial concluded that administration of pembrolizumab, an anti-PD-L1 immune checkpoint inhibitor, together with CRT was safe and tolerable as a first-line therapy for patients with stage III NSCLC (37). However, further research is required to optimise dose, timings, and fractionation of immunotherapy with CRT, while the increased risk of immune-related adverse events, especially pneumonitis and myocarditis, warrants caution in prospective clinical trials $(47,48)$.

\section{CRT in Bladder Cancer}

Finally, bladder cancer has emerged as a promising field of CRT research. Multiple large studies have demonstrated that concurrent CRT offers superior survival compared to radiotherapy alone for muscle invasive bladder cancer (MIBC) [reviewed in (49)]. However, compared to radical cystectomy, CRT offers a lower median OS (32.8 versus 36.1 months) $(50,51)$. Tri-modality therapy consisting of neoadjuvant CRT followed by radical cystectomy has become an acceptable option for the treatment of MIBC, although bladder conservation is not achieved (52). Additionally, there have been critical developments regarding systemic treatment modalities. Cisplatin-based multi-agent chemotherapy has traditionally been the cornerstone systemic treatment for locally advanced and metastatic MIBC in combination with gemcitabine, while carboplatin and taxane-based regimes have been regarded as second-line treatments (53-55).

Combination of CRT with immunotherapy in bladder cancer. Recently, immunotherapy has achieved ground-breaking results in treating bladder cancer. Immune checkpoint inhibitors have gradually replaced cisplatin-based chemotherapy becoming first-line treatment, thus changing the treatment landscape for locally advanced urothelial cancer (56). Moreover, preliminary results from studies suggest that radiation plus immunotherapy not only offers synergistic antitumour effects, notable partial or complete responses, but also an abscopal effect, without excess toxicity (57-59). Thus, combination immunotherapy plus radiotherapy is set to replace CRT alone. Ongoing phase II trials indicate that pembrolizumab plus CRT may be a promising therapeutic option in MIBC $(60,61)$. Thus, a phase III, global, multicentre, double-blind, placebocontrolled, randomized trial has been initiated to evaluate the efficacy and safety of pembrolizumab plus CRT versus placebo plus CRT in MIBC (62). Additionally, the Southwest Oncology Group trial, a randomized phase III study, plans to enrol 475 patients to evaluate CRT-based bladder preservation therapy with and without atezolizumab, a monoclonal antibody to PD-L1 (63). The treatment regimen will include radiotherapy, the physician's choice of chemotherapy, and atezolizumab or placebo. This study is expected to provide more definitive evidence of whether the addition of immunotherapy to CRT increases the chance of successful bladder preservation in patients with MIBC. Results from these trials are awaited.

\section{Conclusion}

CRT is based on the synergistic effects of radiation and chemotherapy in targeting cancer cell death via different mechanisms. Since its original discovery for anal cancer by Nigro, et al. in the 1970s, the use of CRT has expanded vastly, becoming standard therapy for numerous different tumours including cervical, NSCLC, and bladder cancer discussed herein. CRT offers notable patient survival benefits and local disease control without significant increase in longterm toxicities. Yet further research is required to optimise treatments. The advent of immunotherapy is set to change the field remarkably in upcoming years. Several trials are underway to investigate combination regimens of immunotherapy with chemotherapy, radiation, and surgery. 


\section{Conflicts of Interest}

The Authors declare that they have no competing interests.

\section{Authors' Contributions}

K.S.R. contributed to the conceptualization of the work, reviewing the literature, drafting and revising the article, figure illustrations, and final approval of the version to be published. T.H.L.Y. contributed to drafting and revising the article, figure illustrations, and final approval of the version to be published. M.S. contributed to revising the article, supervising the work, and final approval of the version to be published.

\section{References}

1 McRee AJ, Cowherd S, Wang AZ and Goldberg RM: Chemoradiation therapy in the management of gastrointestinal malignancies. Future Oncol 7(3): 409-426, 2011. PMID: 21417904. DOI: $10.2217 /$ fon. 11.7

2 Seiwert TY, Salama JK and Vokes EE: The concurrent chemoradiation paradigm - general principles. Nat Clin Pract Oncol 4(2): 86-100, 2007. PMID: 17259930. DOI: $10.1038 /$ ncponc0714

3 Morgan MA, Parsels LA, Maybaum J and Lawrence TS: Improving the efficacy of chemoradiation with targeted agents. Cancer Discov 4(3): 280-291, 2014. PMID: 24550033. DOI: 10.1158/2159-8290.CD-13-0337

4 Nishimura Y: Rationale for chemoradiotherapy. Int J Clin Oncol 9(6): 414-420, 2004. PMID: 15616871. DOI: 10.1007/s10147004-0443-z

5 Steel GG and Peckham MJ: Exploitable mechanisms in combined radiotherapy-chemotherapy: The concept of additivity. Int J Radiat Oncol 5(1): 85-91, 1979. DOI: 10.1016/03603016(79)90044-0

6 Herscher LL, Cook JA, Pacelli R, Pass HI, Russo A and Mitchell JB: Principles of chemoradiation: theoretical and practical considerations. Oncology 13(10 Suppl 5): 11-22, 1999. PMID: 10550823

7 Nigro ND, Vaitkevicius VK and Considine B: Combined therapy for cancer of the anal canal: A preliminary report. Dis Colon Rectum 17(3): 354-356, 1974. PMID: 4830803. DOI: $10.1007 / \mathrm{bf02586980}$

8 James R, Wan S, Glynne-Jones R, Sebag-Montefiore D, Kadalayil L, Northover J, Cunningham D, Meadows H and Ledermann J: A randomized trial of chemoradiation using mitomycin or cisplatin, with or without maintenance cisplatin/5FU in squamous cell carcinoma of the anus (ACT II). J Clin Oncol 27(18): LBA4009-LBA4009, 2009. DOI: 10.1200/jco.2009.27.18_suppl.lba4009

9 Bartelink H, Roelofsen F, Eschwege F, Rougier P, Bosset JF, Gonzalez DG, Peiffert D, van Glabbeke $\mathrm{M}$ and Pierart M: Concomitant radiotherapy and chemotherapy is superior to radiotherapy alone in the treatment of locally advanced anal cancer: Results of a phase III randomized trial of the European Organization for Research and Treatment of Cancer Radiotherapy and Gastrointestinal Cooperative Groups. J Clin Oncol 15(5): 2040-2049, 1997. PMID: 9164216. DOI: 10.1200/JCO.1997.15.5.2040
10 Flam M, John M, Pajak TF, Petrelli N, Myerson R, Doggett S, Quivey J, Rotman M, Kerman H, Coia L and Murray K: Role of mitomycin in combination with fluorouracil and radiotherapy, and of salvage chemoradiation in the definitive nonsurgical treatment of epidermoid carcinoma of the anal canal: Results of a phase III randomized intergroup study. J Clin Oncol 14(9): 2527-2539, 1996. PMID: 8823332. DOI: 10.1200/JCO.1996.14.9.2527

11 Ajani JA, Winter KA, Gunderson LL, Pedersen J, Benson AB, Thomas CR, Mayer RJ, Haddock MG, Rich TA and Willett C: Fluorouracil, mitomycin, and radiotherapy vs. fluorouracil, cisplatin, and radiotherapy for carcinoma of the anal canal: a randomized controlled trial. JAMA 299(16): 1914-1921, 2008. PMID: 18430910. DOI: 10.1001/jama.299.16.1914

12 UKCCCR Anal Cancer Trial Working Party: Epidermoid anal cancer: Results from the UKCCCR randomised trial of radiotherapy alone versus radiotherapy, 5-fluorouracil, and mitomycin. Lancet Lond Engl 348(9034): 1049-1054, 1996. PMID: 8874455. DOI: 10.1016/S0140-6736(96)03409-5

13 Khosla D, Kumar R, Kapoor R and Sharma SC: Sphincter preservation in anal cancer: A brief review. Saudi J Gastroenterol 19(3): 101, 2013. PMID: 23680706. DOI: 10.4103/13193767.111949

14 Morton GC and Alrashidi SM: High dose rate brachytherapy in high-risk localised disease - why do anything else? Clin Oncol 32(3): 163-169, 2020. PMID: 31791573. DOI: 10.1016/ j.clon.2019.11.003

15 Saarilahti K, Arponen P, Vaalavirta L and Tenhunen M: The effect of intensity-modulated radiotherapy and high-dose-rate brachytherapy on acute and late radiotherapy-related adverse events following chemoradiotherapy of anal cancer. Radiother Oncol 87(3): 383-390, 2008. PMID: 18501454. DOI: $10.1016 /$ j.radonc .2008 .04 .011

16 Prasad RN, Elson J and Kharofa J: The effect of dose escalation for large squamous cell carcinomas of the anal canal. Clin Transl Oncol 20(10): 1314-1320, 2018. PMID: 29623585. DOI: $10.1007 / \mathrm{s} 12094-018-1863-\mathrm{y}$

17 Wegner RE, Abel S, Hasan S, White RJ, Finley G, Monga D, Colonias A and Verma V: Time from stereotactic radiotherapy to immunotherapy is a predictor for outcome in stage IV non-small cell lung cancer. J Immunol Sci 3(2), 2019. DOI: $10.29245 / 2578-3009 / 2019 / 2.1171$

18 Lin A and Ben-Josef E: Intensity-modulated radiation therapy for the treatment of anal cancer. Clin Colorectal Cancer 6(10): 716719, 2007. PMID: 18039425. DOI: 10.3816/CCC.2007.n.041

19 Gupta S, Maheshwari A, Parab P, Mahantshetty U, Hawaldar R, Sastri (Chopra) S, Kerkar R, Engineer R, Tongaonkar H, Ghosh J, Gulia S, Kumar N, Shylasree TS, Gawade R, Kembhavi Y, Gaikar M, Menon S, Thakur M, Shrivastava S and Badwe R: Neoadjuvant chemotherapy followed by radical surgery versus concomitant chemotherapy and radiotherapy in patients with stage IB2, IIA, or IIB squamous cervical cancer: A randomized controlled trial. J Clin Oncol 36(16): 1548-1555, 2018. PMID: 29432076. DOI: 10.1200/JCO.2017.75.9985

20 Todo $\mathrm{Y}$ and Watari $\mathrm{H}$ : Concurrent chemoradiotherapy for cervical cancer: background including evidence-based data, pitfalls of the data, limitation of treatment in certain groups. Chin J Cancer Res 28(2): 221-227, 2016. PMID: 27199520. DOI: $10.21147 /$ j.issn.1000-9604.2016.02.10

21 McCormack M, Kadalayil L, Hackshaw A, Hall-Craggs MA, Symonds RP, Warwick V, Simonds H, Fernando I, Hammond M, 
James L, Feeney A and Ledermann JA: A phase II study of weekly neoadjuvant chemotherapy followed by radical chemoradiation for locally advanced cervical cancer. Br J Cancer 108(12): 2464-2469, 2013. PMID: 23695016. DOI: 10.1038/bjc.2013.230

22 Tripathi A and Rawat S: Comparative study of neoadjuvant chemotherapy followed by definitive chemoradiotherapy versus definitive chemoradiotherapy alone in locally advanced carcinoma of cervix. J Obstet Gynaecol India 69(6): 546-552, 2019. PMID: 31844371. DOI: 10.1007/s13224-019-01236-0

23 Dueñas-González A, Zarbá JJ, Patel F, Alcedo JC, Beslija S, Casanova L, Pattaranutaporn P, Hameed S, Blair JM, Barraclough $\mathrm{H}$ and Orlando $\mathrm{M}$ : Phase III, open-label, randomized study comparing concurrent gemcitabine plus cisplatin and radiation followed by adjuvant gemcitabine and cisplatin versus concurrent cisplatin and radiation in patients with stage IIB to IVA carcinoma of the cervix. J Clin Oncol 29(13): 1678-1685, 2011. PMID: 21444871. DOI: 10.1200/JCO. 2009.25.9663

24 Chemoradiotherapy for Cervical Cancer Meta-Analysis Collaboration: Reducing uncertainties about the effects of chemoradiotherapy for cervical cancer: A systematic review and meta-analysis of individual patient data from 18 randomized trials. J Clin Oncol 26(35): 5802-5812, 2008. PMID: 19001332. DOI: $10.1200 / J C O .2008 .16 .4368$

25 Miller ED, Fisher JL, Haglund KE, Grecula JC, Xu-Welliver M, Bertino EM, He K, Shields PG, Carbone DP, Williams TM, Otterson GA and Bazan JG: The addition of chemotherapy to radiation therapy improves survival in elderly patients with stage III non-small cell lung cancer. J Thorac Oncol 13(3): 426-435, 2018. PMID: 29326090. DOI: 10.1016/j.jtho.2017.11.135

26 Ramalingam S and Belani C: Systemic chemotherapy for advanced non-small cell lung cancer: recent advances and future directions. The Oncologist 13(Suppl 1): 5-13, 2008. PMID: 18263769. DOI: $10.1634 /$ theoncologist.13-S1-5

27 Johnson DH, Einhorn LH, Bartolucci A, Birch R, Omura G, Perez CA and Greco FA: Thoracic radiotherapy does not prolong survival in patients with locally advanced, unresectable nonsmall cell lung cancer. Ann Intern Med 113(1): 33-38, 1990. PMID: 2161633. DOI: 10.7326/0003-4819-113-1-33

28 Perez CA, Pajak TF, Rubin P, Simpson JR, Mohiuddin M, Brady LW, Perez-Tamayo R and Rotman M: Long-term observations of the patterns of failure in patients with unresectable non-oat cell carcinoma of the lung treated with definitive radiotherapy. Report by the Radiation Therapy Oncology Group. Cancer 59(11): 1874-1881, 1987. PMID: 3032394. DOI: 10.1002/10970142(19870601)59:11<1874::aid-cncr2820591106>3.0.co;2-z

29 Provencio M, Isla D, Sánchez A and Cantos B: Inoperable stage III non-small cell lung cancer: current treatment and role of vinorelbine. J Thorac Dis 3(3): 197-204, 2011. PMID: 22263088. DOI: 10.3978/j.issn.2072-1439.2011.01.02

30 O’Rourke N, Roqué I Figuls M, Farré Bernadó N and Macbeth F: Concurrent chemoradiotherapy in non-small cell lung cancer. Cochrane Database Syst Rev 6(6): CD002140, 2010. PMID: 20556756. DOI: 10.1002/14651858.CD002140.pub3

31 Dillman RO, Seagren SL, Propert KJ, Guerra J, Eaton WL, Perry MC, Carey RW, Frei EF and Green MR: A randomized trial of induction chemotherapy plus high-dose radiation versus radiation alone in stage III non-small-cell lung cancer. N Engl J Med 323(14): 940-945, 1990. PMID: 2169587. DOI: 10.1056/NEJM199010043231403
32 Rowell NP and O'Rourke N: Concurrent chemoradiotherapy in non-small cell lung cancer. Cochrane Database Syst Rev 1(4): CD002140, 2004. PMID: 15495029. DOI: 10.1002/14651 858.CD002140.pub2

33 Aupérin A, Le Péchoux C, Rolland E, Curran WJ, Furuse K, Fournel P, Belderbos J, Clamon G, Ulutin HC, Paulus R, Yamanaka T, Bozonnat M-C, Uitterhoeve A, Wang X, Stewart L, Arriagada R, Burdett S and Pignon J-P: Meta-analysis of concomitant versus sequential radiochemotherapy in locally advanced non-small-cell lung cancer. J Clin Oncol 28(13): 21812190, 2010. PMID: 20351327. DOI: 10.1200/JCO.2009.26.2543

34 Curran WJ, Paulus R, Langer CJ, Komaki R, Lee JS, Hauser S, Movsas B, Wasserman T, Rosenthal SA, Gore E, Machtay M, Sause W and Cox JD: Sequential vs. concurrent chemoradiation for stage III non-small cell lung cancer: randomized phase III trial RTOG 9410. JNCI J Natl Cancer Inst 103(19): 1452-1460, 2011. PMID: 21903745. DOI: 10.1093/jnci/djr325

35 Glatzer M, Elicin O, Ramella S, Nestle U and Putora PM: Radio(chemo)therapy in locally advanced non-small cell lung cancer. Eur Respir Rev 25(139): 65-70, 2016. PMID: 26929423. DOI: $10.1183 / 16000617.0053-2015$

36 Bradley JD, Paulus R, Komaki R, Masters G, Blumenschein G, Schild S, Bogart J, Hu C, Forster K, Magliocco A, Kavadi V, Garces YI, Narayan S, Iyengar P, Robinson C, Wynn RB, Koprowski C, Meng J, Beitler J, Gaur R, Curran W and Choy $\mathrm{H}$ : Standard-dose versus high-dose conformal radiotherapy with concurrent and consolidation carboplatin plus paclitaxel with or without cetuximab for patients with stage IIIA or IIIB non-small cell lung cancer (RTOG 0617): A randomised, two-by-two factorial phase 3 study. Lancet Oncol 16(2): 187-199, 2015. PMID: 25601342. DOI: 10.1016/S1470-2045(14)71207-0

37 Jabbour SK, Berman AT and Simone II CB: Integrating immunotherapy into chemoradiation regimens for medically inoperable locally advanced non-small cell lung cancer. Transl Lung Cancer Res 6(2): 113-118-118, 2017. PMID: 28529894. DOI: $10.21037 /$ tlcr.2017.04.02

38 Pembrolizumab, paclitaxel, carboplatin, and radiation therapy in treating patients with stage II-IIIB non-small cell lung cancer ClinicalTrials.gov. Available at: https://www.clinicaltrials.gov/ ct2/show/NCT02621398 [Last accessed December 18, 2020]

39 A phase II trial of concurrent chemoradiation with consolidation pembrolizumab for the treatment of inoperable or unresectable stage III non-small cell lung cancer (NSCLC): HCRN LUN14-179 ClinicalTrials.gov. Available at: https://clinicaltrials.gov/ct2/ show/NCT02343952 [Last accessed December 18, 2020]

40 A global study to assess the effects of MEDI4736 following concurrent chemoradiation in patients with stage III unresectable non-small cell lung cancer (PACIFIC) - ClinicalTrials.gov. Available at: https://clinicaltrials.gov/ct2/show/NCT02125461 [Last accessed December 18, 2020]

41 Nivolumab combination with standard first-line chemotherapy and radiotherapy in locally advanced stage IIIA/B non-small cell lung carcinoma (NICOLAS) - ClinicalTrials.gov. Available at: https://clinicaltrials.gov/ct2/show/NCT02434081 [Last accessed December 18, 2020]

42 DETERRED: PD-L1 blockade to evaluate the safety of lung cancer therapy using carboplatin, paclitaxel, and radiation combined with MPDL3280A - ClinicalTrials.gov. Available at: https://clinicaltrials.gov/ct2/show/NCT02525757 [Last accessed December 18, 2020] 
43 Demaria S and Formenti SC: Radiation as an immunological adjuvant: current evidence on dose and fractionation. Front Oncol 2: 153, 2012. PMID: 23112958. DOI: 10.3389/fonc.2012.00153

44 Golden EB, Frances D, Pellicciotta I, Demaria S, Helen BarcellosHoff $\mathrm{M}$ and Formenti SC: Radiation fosters dose-dependent and chemotherapy-induced immunogenic cell death. Oncoimmunology 3(4): e28518, 2014. PMID: 25071979. DOI: 10.4161/onci.28518

45 McBride WH, Chiang C-S, Olson JL, Wang C-C, Hong J-H, Pajonk F, Dougherty GJ, Iwamoto KS, Pervan M and Liao Y-P: A sense of danger from radiation. Radiat Res 162(1): 1-19, 2004. PMID: 15222781. DOI: 10.1667/RR3196

46 Postow MA, Callahan MK, Barker CA, Yamada Y, Yuan J, Kitano S, Mu Z, Rasalan T, Adamow M, Ritter E, Sedrak C, Jungbluth AA, Chua R, Yang AS, Roman R-A, Rosner S, Benson B, Allison JP, Lesokhin AM, Gnjatic S and Wolchok JD: Immunologic correlates of the abscopal effect in a patient with melanoma. N Engl J Med 366(10): 925-931, 2012. PMID: 22397654. DOI: 10.1056/NEJMoa1112824

47 Naidoo J, Wang X, Woo KM, Iyriboz T, Halpenny D, Cunningham J, Chaft JE, Segal NH, Callahan MK, Lesokhin AM, Rosenberg J, Voss MH, Rudin CM, Rizvi H, Hou X, Rodriguez K, Albano M, Gordon R-A, Leduc C, Rekhtman N, Harris B, Menzies AM, Guminski AD, Carlino MS, Kong BY, Wolchok JD, Postow MA, Long GV and Hellmann MD: Pneumonitis in patients treated with anti-programmed death1/programmed death ligand 1 therapy. J Clin Oncol 35(7): 709717, 2017. PMID: 27646942. DOI: 10.1200/JCO.2016.68.2005

48 Johnson DB, Balko JM, Compton ML, Chalkias S, Gorham J, Xu Y, Hicks M, Puzanov I, Alexander MR, Bloomer TL, Becker JR, Slosky DA, Phillips EJ, Pilkinton MA, Craig-Owens L, Kola N, Plautz G, Reshef DS, Deutsch JS, Deering RP, Olenchock BA, Lichtman AH, Roden DM, Seidman CE, Koralnik IJ, Seidman JG, Hoffman RD, Taube JM, Diaz LA, Anders RA, Sosman JA and Moslehi JJ: Fulminant myocarditis with combination immune checkpoint blockade. N Engl J Med 375(18): 1749-1755, 2016. PMID: 27806233. DOI: 10.1056/NEJMoa1609214

49 Ghate K, Brennan K, Karim S, Siemens DR, Mackillop WJ and Booth CM: Concurrent chemoradiotherapy for bladder cancer: Practice patterns and outcomes in the general population. Radiother Oncol J 127(1): 136-142, 2018. PMID: 29306498. DOI: 10.1016/j.radonc.2017.12.009

50 Haque W, Verma V, Butler EB and Teh BS: Radical cystectomy versus chemoradiation for muscle-invasive bladder cancer: Impact of treatment facility and sociodemographics. Anticancer Res 37(10): 5603-5608, 2017. PMID: 28982876. DOI: 10.21873/anticanres.11994

51 Ritch CR, Balise R, Prakash NS, Alonzo D, Almengo K, Alameddine M, Venkatramani V, Punnen S, Parekh DJ and Gonzalgo ML: Propensity matched comparative analysis of survival following chemoradiation or radical cystectomy for muscle-invasive bladder cancer. BJU Int 121(5): 745-751, 2018. PMID: 29281848. DOI: 10.1111/bju.14109

52 Leitlinienreport der S3-Leitline zur Früherkennung, Diagnose, Therapie und Nachsorge des Harnblasenkarzinoms Leitlinienprogramm Onkologie. Available at: https://www.awmf. org/uploads/tx_szleitlinien/032-038ol_m_S3_Harnblasenkarzinom _2016-12.pdf [Last accessed December 21, 2020]

53 Teply BA and Kim JJ: Systemic therapy for bladder cancer - a medical oncologist's perspective. J Solid Tumors 4(2): 25-35, 2014. PMID: 25404954. DOI: 10.5430/jst.v4n2p25
54 Witjes JA, Lebret T, Compérat EM, Cowan NC, Santis MD, Bruins HM, Hernández V, Espinós EL, Dunn J, Rouanne M, Neuzillet Y, Veskimäe E, Heijden AG van der, Gakis G and Ribal MJ: Updated 2016 EAU guidelines on muscle-invasive and metastatic bladder cancer. Eur Urol 71(3): 462-475, 2017. PMID: 27375033. DOI: 10.1016/j.eururo.2016.06.020

55 Pinto IG: Systemic therapy in bladder cancer. Indian J Urol 33(2): 118-126, 2017. PMID: 28469299. DOI: 10.4103/iju.IJU_294_16

56 Crist $M$, Iyer $G$, Hsu $M$, Huang $W C$ and Balar AV: Pembrolizumab in the treatment of locally advanced or metastatic urothelial carcinoma: Clinical trial evidence and experience. Ther Adv Urol 11(1): 1-9, 2019. PMID: 31057668. DOI: $10.1177 / 1756287219839285$

57 Kang J, Demaria S and Formenti S: Current clinical trials testing the combination of immunotherapy with radiotherapy. J Immunother Cancer 4(1): 51, 2016. PMID: 27660705. DOI: 10.1186/s40425-016-0156-7

58 Krcik EM: Radiation therapy plus anti-programmed death ligand 1 immunotherapy: A review on overall survival. Radiol Technol 88(1): 123-128, 2016. PMID: 27601709.

59 Van Limbergen EJ, De Ruysscher DK, Olivo Pimentel V, Marcus D, Berbee M, Hoeben A, Rekers N, Theys J, Yaromina A, Dubois LJ and Lambin P: Combining radiotherapy with immunotherapy: The past, the present and the future. $\mathrm{Br} \mathrm{J}$ Radiol 90(1076): 20170157, 2017. DOI: 10.1259/bjr.20170157

60 Pembrolizumab (MK3475), gemcitabine, and concurrent hypofractionated radiation therapy for muscle-invasive urothelial cancer of the bladder - ClinicalTrials.gov. Available at: https://clinicaltrials.gov/ct2/show/NCT02621151 [Last accessed December 3, 2020]

61 Weickhardt AJ, Foroudi F, Sengupta S, Galletta L, Herschtal A, Grimison PS, Patanjali N, Ng S, Tang C, Goodwin R, Hovey EJ, Jarvis T, Chen C, Sandhu SK, Tai KH, Lawrentschuk N and Davis ID: Pembrolizumab and chemoradiotherapy for muscle invasive bladder cancer: The ANZUP 1502 PCR-MIB trial. J Clin Oncol 36(6): TPS531-TPS531, 2018. DOI: 10.1200/ JCO.2018.36.6_suppl.TPS531

62 Balar AV, James ND, Shariat SF, Shore ND, Van Der Heijden MS, Weickhardt AJ, Fang X, Godwin JL, Kapadia E and Michalski JM: Phase III study of pembrolizumab (pembro) plus chemoradiotherapy (CRT) versus CRT alone for patients (pts) with muscle-invasive bladder cancer (MIBC): KEYNOTE-992. J Clin Oncol 38(15): TPS5093-TPS5093, 2020. DOI: 10.1200/JCO.2020.38.15_suppl.TPS5093

63 Singh P, Tangen C, Efstathiou JA, Lerner SP, Jhavar SG, Hahn NM, Costello BA, Sridhar SS, Du W, Meeks JJ, Faltas BM, Grivas P, Feng FY, Chen RC, Morgans AK, Gupta A, Bangs RC, Winter KA, Vogelzang NJ and Thompson IM: INTACT: Phase III randomized trial of concurrent chemoradiotherapy with or without atezolizumab in localized muscle invasive bladder cancer-SWOG/NRG1806. J Clin Oncol 38(6): TPS586TPS586, 2020. DOI: 10.1200/JCO.2020.38.6_suppl.TPS586

Received December 4, 2020

Revised December 18, 2020

Accepted December 21, 2020 